\title{
Extracting Deflation Probability Forecasts from Treasury Yields
}

\author{
Jens H. E. Christensen \\ Federal Reserve Bank of San Francisco \\ Jose A. Lopez \\ Federal Reserve Bank of San Francisco \\ Glenn D. Rudebusch \\ Federal Reserve Bank of San Francisco
}

\begin{abstract}
February 2011
Working Paper 2011-10

http://www.frbsf.org/publications/economics/papers/2011/wp11-10bk.pdf
\end{abstract}

The views in this paper are solely the responsibility of the authors and should not be interpreted as reflecting the views of the Federal Reserve Bank of San Francisco or the Board of Governors of the Federal Reserve System. 


\title{
Extracting Deflation Probability Forecasts from Treasury Yields
}

\author{
Jens H. E. Christensen, \\ Jose A. Lopez, \\ and \\ Glenn D. Rudebusch \\ Federal Reserve Bank of San Francisco \\ 101 Market Street, Mailstop 1130 \\ San Francisco, CA 94105
}

\begin{abstract}
We construct probability forecasts for episodes of price deflation (i.e., a falling price level) using yields on nominal and real U.S. Treasury bonds. The deflation probability forecasts identify two "deflation scares" during the past decade: a mild one following the 2001 recession, and a more serious one starting in late 2008 with the deepening of the financial crisis. The estimated deflation probabilities are generally consistent with those from macroeconomic models and surveys of professional forecasters, but they also provide highfrequency insight into the views of financial market participants. The probabilities can also be used to price the deflation option embedded in real Treasury bonds.
\end{abstract}

We thank participants at the IBEFA-ASSA Session in Denver 2011 for helpful comments, especially our discussant James Wilcox. We thank James Gillan and Justin Weidner for excellent research assistance. The views in this paper are solely the responsibility of the authors and should not be interpreted as reflecting the views of the Federal Reserve Bank of San Francisco or the Board of Governors of the Federal Reserve System.

This version: February 15, 2011. 


\section{Introduction}

Throughout much of the postwar period, as overall price levels rose fairly rapidly in many countries, central banks were concerned with reducing price inflation in order to achieve their mandate for price stability. However, in recent years, as inflation rates around the world have fallen to much lower levels, the risks to price stability have become more symmetric, and fears that inflation may fall too low have emerged. In particular, the risk of negative inflation - price deflation - has become a recurring concern for several central banks. ${ }^{1}$ Most seriously, Japan has been mired in deflation and economic stagnation since the mid-1990s.

Among Federal Reserve policymakers, worries about deflation surfaced twice during the past decade. The first episode followed the 2001 recession. Notably, the Federal Open Market Committee's (FOMC) statement of May 6, 2003 publicly expressed the possibility of an "unwelcome substantial fall in inflation." Then Federal Reserve Governor Ben Bernanke (2003) highlighted the importance of this statement, noting that "[t]he May 6 statement broke new ground as the first occasion in which the FOMC expressed the concern that inflation might actually fall too low." The second period of deflationary worries began during the recent financial crisis and ensuing recession. In the wake of a deepening worldwide financial upheaval in late 2008, projections of a slowing economy and possible price deflation were key drivers of monetary policy. Federal Reserve Chairman Bernanke (2010) described the motivation for policy actions during the crisis in this way: "[T]he FOMC's policy response also reflected concerns about a possible unwelcome decline in inflation. Taking note of the painful experience of Japan, policymakers worried that the United States might sink into deflation and that, as one consequence, the FOMC's target interest rate might hit its zero lower bound, limiting the scope for further monetary accommodation."

The desire to avoid deflation is often based on the view that a deflationary episode is particularly treacherous. Early on, Bernanke (2003) stressed the pernicious effects of deflation: "In any case, I hope we can agree that a substantial fall in inflation at this stage has the potential to interfere with the ongoing U.S. recovery, and that in conceivable - although remote - circumstances, a serious deflation would do significant economic harm." Deflationary episodes are considered especially worrying because they may have their own unique and painful dynamics. The continuing deflationary travails of Japan illustrate the possibility that the interaction of price deflation with the zero lower bound on nominal interest rates may produce an intractable regime that is difficult to exit. Even worse, some theoretical models

\footnotetext{
${ }^{1}$ See Bordo and Filardo (2005) and Kumar et al. (2003) for historical and cross-county surveys of deflationary episodes.
} 
suggest that a reinforcing and escalating "deflationary spiral" could arise at the zero bound, in which the fall in prices boosts real interest rates and vice versa. In addition, deflations also may carry particularly severe social costs related to the increased real burden on borrowers with fixed nominal debts. If deflations are special regimes that have their own unique dynamics or social costs, it would be particularly useful to go beyond point forecasts of inflation and consider probability forecasts for the occurrence of a deflationary episode. ${ }^{2}$

Given the special interest in periods of price deflation, we examine probability forecasts for such episodes. Of course, there are a variety of ways in which deflation probability forecasts could be constructed. In this paper, we focus on high-frequency probability forecasts that are derived from yields on nominal and real Treasury bonds. While nominal Treasury bonds have fixed coupons and principal, real Treasury bonds - or Treasury inflation-protected securities (TIPS) - have coupons and principal that vary with changes in the headline consumer price index (CPI). Differences between comparable-maturity nominal and real yields are widely used as readings on the inflation expectations of market participants; however, such readings are obscured by fluctuations in the compensation for inflation risk. To disentangle inflation expectations and risk premiums, Christensen et al. (2010), henceforth CLR, use an affine, arbitrage-free dynamic term structure of nominal and real yields. ${ }^{3}$ In this paper, we show how to use such a dynamic term structure model to calculate the entire probability distribution of future inflation outcomes - particularly, the implied deflation probability forecasts - at any forecast horizon.

Our deflation probability forecasts estimated from yield curves align well with the results from simple macroeconomic benchmarks, surveys of professional forecasters, and other financial market prices. These comparisons provide some assurance that our "yields-only" approach provides useful deflation probabilities under the "real-world" pricing measure needed for macroeconomic policy analysis and risk management (as opposed to just the "risk-neutral" pricing measure). Furthermore, we demonstrate how the deflation probability forecasts can be used to value the deflation protection option embedded in TIPS bonds exploiting the AF property of the model. ${ }^{4}$ Our results show that the model-implied value of the embedded de-

\footnotetext{
${ }^{2}$ Similar arguments have long been used to motivate the widespread focus on recession probability forecasts. That is, since recessions are exceptional episodes or regimes worthy of special attention, it is useful to consider event probabilities instead of just point forecasts of future growth (e.g., Diebold and Rudebusch 1989, Rudebusch and Williams 2009).

${ }^{3}$ Arbitrage-free (AF) models specify the risk-neutral evolution of the underlying yield-curve factors as well as the dynamics of risk premiums under the key theoretical restriction that there are no residual opportunities for riskless arbitrage across maturities and over time. Note that these models provide pricing information under both the risk-neutral and observed (or "real-world") pricing measures.

${ }^{4}$ To the best of our knowledge, Grishchenko et al. (2010) is the only other paper to explicitly address the valuation of the deflation protection embedded in TIPS bonds within a dynamic term structure model.
} 
flation protection is highly correlated with the observed price difference between TIPS bonds of similar remaining maturities but different degrees of accumulated inflation exposure.

Our discussion proceeds as follows. Section 2 summarizes the AF model and describes how deflation probability forecasts are obtained from a full-sample model estimate (i.e., in-sample fitted values) and from real-time model estimates based on expanding samples (i.e., out-ofsample forecasts). The resulting deflation probabilities suggest that over the past decade two "deflation scares" occurred: a mild one following the 2001 recession, and a more serious one that started in the autumn of 2008 after the deepening of the worldwide financial crisis. In Section 3, we compare our real-time deflation probability forecasts based on Treasury yields to a variety of alternative forecasts from macroeconomic models and surveys. These alternative forecasts are roughly in line with our estimates, but their low frequency makes them less useful as indicators of future deflation in real time. In Section 4, we compare our real-time forecasts to alternatives in the finance literature that are based on yield differentials between seasoned and newly-issued TIPS. These alternative measures contain no correction for risk premiums and are thus expressed in risk-neutral pricing terms. Using an AF model, we can generate similar deflation probabilities under the risk-neutral pricing measure; however, our focus is on deflation probabilities under the alternative "real-world" pricing measure, which is more relevant for macroeconomic policy and risk management. Indeed, Section 5 provides a salient example of the model's asset pricing applications by valuing the deflation protection option embedded in the principal payments of TIPS bonds.

\section{Deflation Probabilities from a Term Structure Model}

A dynamic term structure model can be used to decompose differences between nominal and real yield curves into market-implied inflation expectations and inflation risk premiums at various maturities. Such models can also provide information on the full distribution of expected inflation outcomes. In this section, we summarize the CLR version of such a model and explain how to obtain the implied deflation probabilities.

\subsection{CLR Model Specification}

Affine, arbitrage-free term structure models, of which the CLR model is an example, link yield curve dynamics and investor risk premiums within a consistent framework that can produce both risk-neutral and real-world representations of yield curves over time. Denote the nominal and real stochastic discount factors as $M_{t}^{N}$ and $M_{t}^{R}$, respectively. The price of a 
nominal bond that pays one dollar at time $\tau$ and the price of a real bond that pays one unit of the consumption basket at time $\tau$ are written as

$$
P_{t}^{N}(\tau)=E_{t}^{P}\left[\frac{M_{t+\tau}^{N}}{M_{t}^{N}}\right] \quad \text { and } \quad P_{t}^{R}(\tau)=E_{t}^{P}\left[\frac{M_{t+\tau}^{R}}{M_{t}^{R}}\right]
$$

The no-arbitrage condition requires a consistency between the prices of nominal and real bonds such that the price of the consumption basket, denoted as the overall price level $Q_{t}$, is the ratio of the stochastic discount factors:

$$
Q_{t}=\frac{M_{t}^{R}}{M_{t}^{N}}
$$

As derived in CLR, the relationship between nominal and real zero-coupon yields with maturity $\tau$ at time $t$, denoted as $y_{t}^{N}(\tau)$ and $y_{t}^{R}(\tau)$, and expected inflation is

$$
y_{t}^{N}(\tau)=y_{t}^{R}(\tau)+\pi_{t}^{e}(\tau)+\phi_{t}(\tau)
$$

where the market-implied rate of inflation expected at time $t$ for the period from $t$ to $t+\tau$ is

$$
\pi_{t}^{e}(\tau)=-\frac{1}{\tau} \ln E_{t}^{P}\left[\frac{Q_{t}}{Q_{t+\tau}}\right]=-\frac{1}{\tau} \ln E_{t}^{P}\left[e^{-\int_{t}^{t+\tau}\left(r_{s}^{N}-r_{s}^{R}\right) d s}\right]
$$

where $r_{t}^{N}$ and $r_{t}^{R}$ are the instantaneous nominal and real risk-free rates. The corresponding inflation risk premium is denoted as

$$
\phi_{t}(\tau)=-\frac{1}{\tau} \ln \left(1+\frac{\operatorname{cov}_{t}^{P}\left[\frac{M_{t+\tau}^{R}}{M_{t}^{R}}, \frac{Q_{t}}{Q_{t+\tau}}\right]}{E_{t}^{P}\left[\frac{M_{t+\tau}^{R}}{M_{t}^{R}}\right] \times E_{t}^{P}\left[\frac{Q_{t}}{Q_{t+\tau}}\right]}\right) .
$$

The CLR model is a four-factor version of the arbitrage-free Nelson-Siegel (AFNS) representation developed by Christensen et al. (CDR, 2010). The first three factors correspond to the level, slope and curvature factors commonly observed for nominal yields and denoted $L_{t}^{N}, S_{t}$, and $C_{t}$, respectively. The fourth factor, $L_{t}^{R}$, corresponds to the level factor for real yields. The state vector is thus defined as $X_{t}=\left(L_{t}^{N}, S_{t}, C_{t}, L_{t}^{R}\right)$. The instantaneous nominal and real risk-free rates are set to be

$$
\begin{aligned}
& r_{t}^{N}=L_{t}^{N}+S_{t}, \\
& r_{t}^{R}=L_{t}^{R}+\alpha^{R} S_{t},
\end{aligned}
$$


where the differential scaling of real rates to the common slope factor is captured by the parameter $\alpha^{R}$. Within this framework, nominal Treasury zero-coupon bond yields are denoted as

$$
y_{t}^{N}(\tau)=L_{t}^{N}+\left(\frac{1-e^{-\lambda \tau}}{\lambda \tau}\right) S_{t}+\left(\frac{1-e^{-\lambda \tau}}{\lambda \tau}-e^{-\lambda \tau}\right) C_{t}+\frac{A^{N}(\tau)}{\tau}
$$

where $A^{N}(\tau) / \tau$ is a nominal yield-adjustment term. The real TIPS zero-coupon bond yields are

$$
y_{t}^{R}(\tau)=L_{t}^{R}+\alpha^{R}\left(\frac{1-e^{-\lambda \tau}}{\lambda \tau}\right) S_{t}+\alpha^{R}\left(\frac{1-e^{-\lambda \tau}}{\lambda \tau}-e^{-\lambda \tau}\right) C_{t}+\frac{A^{R}(\tau)}{\tau}
$$

where $A^{R}(\tau) / \tau$ is a real yield-adjustment term. These two equations when combined in state-space form constitute the measurement equation within our Kalman filter estimation.

To complete the model, we define the price of risk, which determines the connection between the risk-neutral and real-world yield dynamics. We assume that the nominal and real stochastic discount factors have standard dynamics given by $d M_{t}^{N} / M_{t}^{N}=-r_{t}^{N} d t-\Gamma_{t}^{\prime} d W_{t}^{P}$ and $d M_{t}^{R} / M_{t}^{R}=-r_{t}^{R} d t-\Gamma_{t}^{\prime} d W_{t}^{P}$, where $W_{t}^{P}$ is a Brownian motion process. We use the essentially affine risk premium specification introduced by Duffee (2002), so the risk premium $\Gamma_{t}$ is defined by the measure change

$$
d W_{t}^{Q}=d W_{t}^{P}+\Gamma_{t} d t
$$

with $\Gamma_{t}=\gamma^{0}+\gamma^{1} X_{t}, \gamma^{0} \in \mathbf{R}^{4}$, and $\gamma^{1} \in \mathbf{R}^{4 \times 4}$. Therefore, the real-world dynamics of the state variables can be expressed as

$$
d X_{t}=K^{P}\left(\theta^{P}-X_{t}\right) d t+\Sigma d W_{t}^{P}
$$

In the unrestricted case, both $K^{P}$ and $\theta^{P}$ are allowed to vary freely, but CLR provide a detailed empirical analysis to justify various zero-value restrictions on the $K^{P}$ matrix. Imposing these restrictions results in the equation

$$
\left(\begin{array}{c}
d L_{t}^{N} \\
d S_{t} \\
d C_{t} \\
d L_{t}^{R}
\end{array}\right)=\left(\begin{array}{cccc}
\kappa_{11}^{P} & 0 & 0 & \kappa_{14}^{P} \\
\kappa_{21}^{P} & \kappa_{22}^{P} & \kappa_{23}^{P} & 0 \\
0 & 0 & \kappa_{33}^{P} & 0 \\
\kappa_{41}^{P} & \kappa_{42}^{P} & 0 & \kappa_{44}^{P}
\end{array}\right)\left(\left(\begin{array}{c}
\theta_{1}^{P} \\
\theta_{2}^{P} \\
\theta_{3}^{P} \\
\theta_{4}^{P}
\end{array}\right)-\left(\begin{array}{c}
L_{t}^{N} \\
S_{t} \\
C_{t} \\
L_{t}^{R}
\end{array}\right)\right) d t+\Sigma\left(\begin{array}{c}
d W_{t}^{P, L^{N}} \\
d W_{t}^{P, S} \\
d W_{t}^{P, C} \\
d W_{t}^{P, L^{R}}
\end{array}\right),
$$


where the covariance matrix $\Sigma$ is assumed diagonal and constant. This is the transition equation in our Kalman filter estimation.

\subsection{Calculation of Deflation Probabilities}

Using the CLR model, we can examine whether the change in the price index (i.e., the inflation rate) from time $t$ to $t+\tau$ will fall below a certain critical level $q$. This event is denoted as

$$
\frac{Q_{t+\tau}}{Q_{t}}=e^{\int_{t}^{t+\tau}\left(r_{s}^{N}-r_{s}^{R}\right) d s} \leq(1+q)
$$

Taking logs, this expression is equivalent to

$$
Y_{t, t+\tau}=\ln \left(\frac{Q_{t+\tau}}{Q_{t}}\right)=\int_{t}^{t+\tau}\left(r_{s}^{N}-r_{s}^{R}\right) d s \leq \ln (1+q) .
$$

As shown in the appendix, the conditional distribution of this integral term is

$$
Y_{t, t+\tau} \sim N\left(m_{Y}^{P}(t, \tau), \sigma_{Y}^{P}(\tau)^{2}\right)
$$

where $m_{Y}^{P}(t, \tau)$ and $\sigma_{Y}^{P}(\tau)^{2}$ are the distribution's conditional mean and variance, respectively, under the real-world probability measure. ${ }^{5}$ The probability of the change in the price index being below the critical level $q$ is therefore equivalent to

$\operatorname{Prob}_{t}\left(Y_{t, t+\tau} \leq \ln (1+q)\right)=\operatorname{Prob}_{t}\left(\frac{Y_{t, t+\tau}-m_{Y}^{P}(t, \tau)}{\sigma_{Y}^{P}(\tau)} \leq \frac{\ln (1+q)-m_{Y}^{P}(t, \tau)}{\sigma_{Y}^{P}(\tau)}\right)=\Phi\left(\frac{\ln (1+q)-m_{Y}^{P}(t, \tau)}{\sigma_{Y}^{P}(\tau)}\right)$.

To assess deflationary outcomes, $q=0$, and

$$
\operatorname{Prob}_{t}\left(Y_{t, t+\tau} \leq 0\right)=\Phi\left(\frac{-m_{Y}^{P}(t, \tau)}{\sigma_{Y}^{P}(\tau)}\right)
$$

\subsection{Full-Sample Deflation Probability Estimates}

We start with a full-sample examination of the model and its fitted (or in-sample) deflation probabilities. For this estimation, we use nominal Treasury zero-coupon bond yields with maturities of 3 and 6 months, and 1, 2, 3, 5, 7, and 10 years from January 3, 1995 to December 7, 2010, for a total of 3,978 daily observations. We also use real TIPS bond yields with maturities of 5, 6, 7, 8, 9, and 10 years from January 4, 1999, to December 7, 2010, for a total of daily 2,980 observations. ${ }^{6}$ The U.S. Treasury first issued TIPS in 1997, but

\footnotetext{
${ }^{5}$ Risk-neutral inflation probabilities are readily obtained by replacing the real-world dynamics of the state variables with their risk-neutral dynamics.

${ }^{6}$ The data are described in Gürkaynak et al. $(2007,2010)$ and are available from the Board of Governors of the Federal Reserve website. Nominal yields are constructed from off-the-run Treasury bonds, while real
} 


\begin{tabular}{|c|cccc||c||c|c|}
\hline$K^{P}$ & $K_{,, 1}^{P}$ & $K_{\cdot, 2}^{P}$ & $K_{\cdot, 3}^{P}$ & $K_{\cdot, 4}^{P}$ & $\theta^{P}$ & & $\Sigma$ \\
\hline$K_{1, \cdot}^{P}$ & 0.5999 & 0 & 0 & -0.3719 & 0.0614 & $\Sigma_{1,1}$ & 0.0052 \\
& $(0.2539)$ & & & $(0.2157)$ & $(0.0039)$ & & $(0.0001)$ \\
$K_{2, \cdot}^{P}$ & 1.1921 & 0.6820 & -0.6698 & 0 & -0.0288 & $\Sigma_{2,2}$ & 0.0082 \\
& $(0.3873)$ & $(0.1561)$ & $(0.1055)$ & & $(0.0105)$ & & $(0.0001)$ \\
$K_{3, \cdot}^{P}$ & 0 & 0 & 0.6070 & 0 & -0.0215 & $\Sigma_{3,3}$ & 0.0324 \\
& & & $(0.2584)$ & & $(0.0094)$ & & $(0.0002)$ \\
$K_{4, \cdot}^{P}$ & -3.2348 & -0.5551 & 0 & 2.3674 & 0.0340 & $\Sigma_{4,4}$ & 0.0063 \\
& $(0.4303)$ & $(0.1213)$ & & $(0.3198)$ & $(0.0047)$ & & $(0.0001)$ \\
\hline
\end{tabular}

Table 1: Parameter Estimates for the Preferred Specification of the CLR Model. The estimated parameters of the $K^{P}$ matrix, $\theta^{P}$ vector, and diagonal $\Sigma$ matrix are shown for the preferred specification of the CLR model. The estimated value of $\lambda$ is $0.4925(0.0015)$, while $\alpha^{R}$ is estimated to be $0.5323(0.0017)$. The numbers in parentheses are the estimated parameter standard deviations. The maximum log likelihood value is $298,501.8$.

for several years afterward, the liquidity of the secondary TIPS market was impaired by the small amount of securities outstanding and uncertainty about the Treasury's commitment to the program. Indeed, to avoid the illiquid nascent years of this market, CLR began their estimation sample of TIPS yields in 2003. Here, in order to shed some light on deflation probabilities early in the 2000s, we start our sample of TIPS data earlier, which does not significantly affect our later conclusions.

Table 1 presents the estimated parameters of the preferred CLR model specification over the full sample. The estimates are comparable to those given in CLR for a shorter sample of weekly data. In particular, the off-diagonal elements in the estimated $K^{P}$ matrix are highly statistically significant except for $\kappa_{14}^{P}$, which has seen its significance decline since the onset of the financial crisis. However, a robustness check indicates that this parameter has a negligible effect on the fitted, in-sample deflation probabilities, therefore we proceed with the preferred CLR specification throughout the paper.

Figure 1 shows our full sample estimates of the one-year probability of deflation (i.e., $q=0$ and $\tau$ equals one year). Using a rough benchmark of a probability greater than five percent, two "deflation scare" episodes stand out. Outside these two periods of elevated deflation risk, the estimated deflation probability is effectively zero.

Figure 2 puts the two deflation scares into sharper focus along with grey shading to indicate recessions. Both episodes were preceded by recessions, but in each case, the risk of deflation persisted long after the recessions ended. The first episode spans September 2001 through December 2003. During this period, as noted in the introduction, the FOMC yields are based on both on-the-run and off-the-run TIPS bonds. 


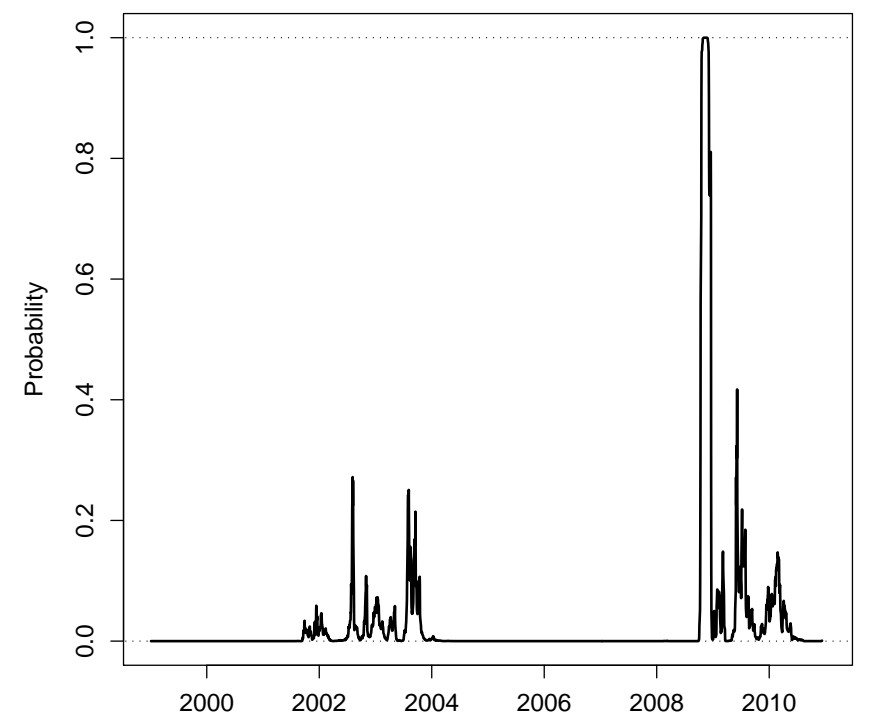

Figure 1: In-Sample One-Year Deflation Probabilities.

Illustration of the probability of non-positive net inflation (or deflation) over the forthcoming year as estimated by the CLR model over the full sample period.

expressed concern for the first time that inflation might fall too low. The one-year marketimplied deflation probability averaged $3.0 \%$ over this period, reaching highs of over $25 \%$ in August 2002 and August 2003. During this 28-month period, negative month-to-month values for headline CPI inflation were recorded six times. The second deflation scare episode begins shortly after the Lehman Brothers bankruptcy on September 15, 2008 and runs through April 2010. This episode is marked by a sharp spike in the fitted, one-year deflation probabilities up to near certainty in late October and early November 2008. In response to concerns of a very severe and rapid economic collapse, the Federal Reserve enacted a variety of conventional and unconventional monetary and liquidity policy actions, which likely helped reduce the probabilities in the first quarter of 2009 to an average of $4.3 \%$ with temporary spikes up to 15 percent. The model's one-year-ahead deflation probabilities averaged $5.3 \%$ over the course of 2009. The probabilities averaged $2.6 \%$ for the dataset in 2010 and dipped below $5 \%$ in April. Over this 20 month period, seven months registered negative, month-to-month values for headline CPI with annualized values of more than $-10 \%$ in October and November 2008.

The very high deflation probabilities immediately after the Lehman bankruptcy certainly reflect the widespread fear of a resulting global macroeconomic free fall, but they are also likely 


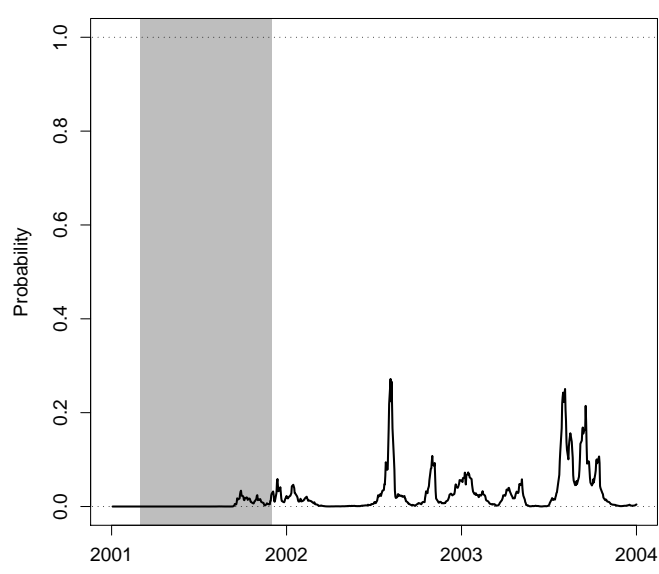

(a) First deflation scare.

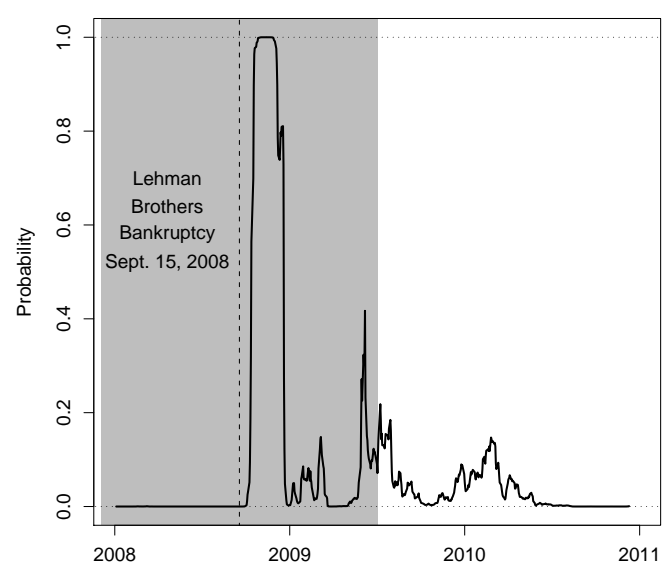

(b) Second deflation scare.

Figure 2: In-Sample Deflation Probabilities over the Defined Deflation Scares.

Illustration of the fitted, in-sample one-year deflation probabilities from the preferred specification of the CLR model over the defined deflation scares (i.e., probability $>5 \%$ ). Shown in grey shading are recessions as determined by the NBER.

boosted by market illiquidity during the financial crisis. Several asset classes faced impaired liquidity during the fall of 2008 with widening bid-ask spreads, lower trading volumes, and concurrent increases in yields. The jump in risk aversion also helped create a heightened global demand for safe assets, and this "flight-to-quality" (or "safe haven") demand favored highly liquid nominal Treasury securities and led to a sharp decline in their yields, while real yields declined by less. Liquidity in the TIPS market was especially hard hit (see Campbell et al. 2009 and CLR for detailed discussions), which lead to higher real yields and a narrowing of spreads to nominal Treasuries. The model's deflation probabilities are certainly boosted during the last few months of 2008 due to these liquidity events, but this volatile period of very high deflation probabilities appears to have been relatively short in nature.

\subsection{Real-time Deflation Probability Forecasts}

In order to generate deflation forecast probabilities that would be relevant to market participants and policymakers in real time, we complement our fitted, in-sample estimates with deflation probabilities based on expanding-sample model estimations. In particular, we reestimate the preferred specification of the model using weekly data with end of sample dates from January 7, 2005 to December 3, 2010, a total of 309 estimations. $^{7}$ We start this analysis

\footnotetext{
${ }^{7}$ That is, starting with the first week of January 2005, each new weekly observation is included in the sample, and the model is re-estimated. Note that the shift to weekly data from daily data had little effect on
} 


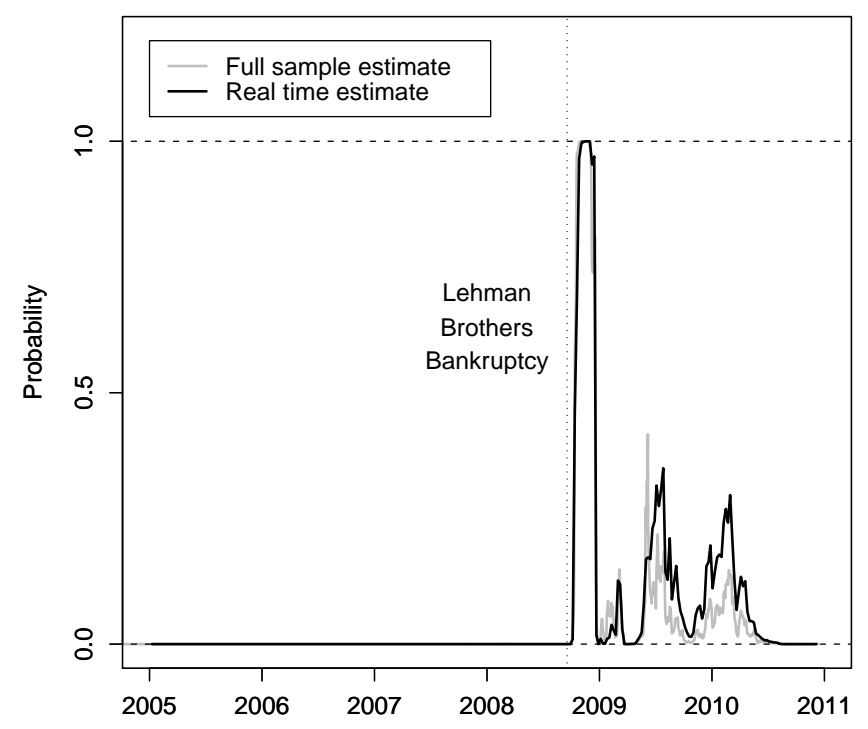

Figure 3: Real-Time, One-Year Probability Forecasts of Deflation.

Illustration of the real-time, out-of-sample probabilities of non-positive net inflation (i.e., deflation) over the following year as estimated by the CLR model. Included are the corresponding estimates from the full sample estimation.

in 2005 in order to provide a minimum sample size for accurate estimation and thus cannot examine the earlier deflation episode in this manner.

Figure 3 shows that inference based on the two sets of default probabilities does not change qualitatively. To provide further context for these deflation probability forecasts, Figure 4 examines the ability of the model's point estimates of one-year-ahead expected inflation to track actually observed inflation rates. In Figure 4(a), we graph these expectations relative to the corresponding observed year-over-year changes in headline CPI, which is the index used for TIPS bonds. Note that the model does well at predicting deflation in 2009 as headline CPI in May 2009 was 2.1 percent below its level the year before. However, the model does not capture the volatile short-term variation in headline CPI. Such volatility is driven by fluctuations in crude food and energy prices which are notoriously difficult to forecast. Therefore, in Figure 4(b), we compare the model's one-year inflation expectations to the observed year-over-year changes in the less volatile core CPI series. The model tracks these changes remarkably well using both estimation samples. Thus, the model and its deflation probabilities may be useful tools for real-time macroeconomic policy or historical analysis.

our analysis but speeded the re-estimation process. 


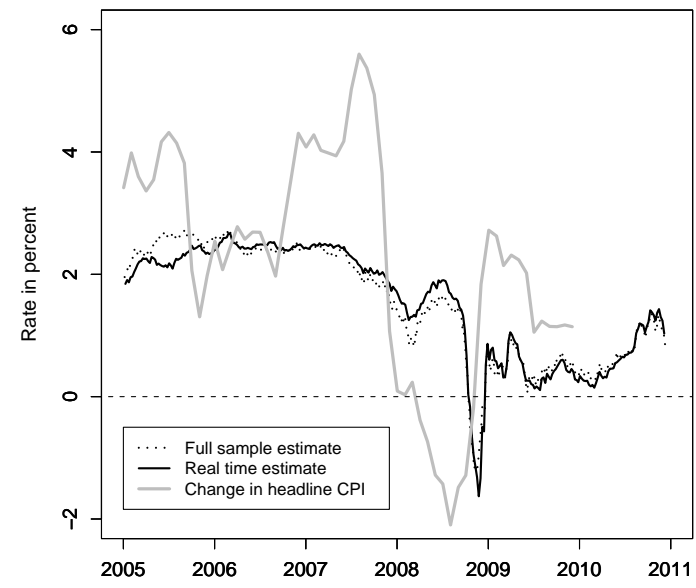

(a) Comparison to headline CPI inflation.

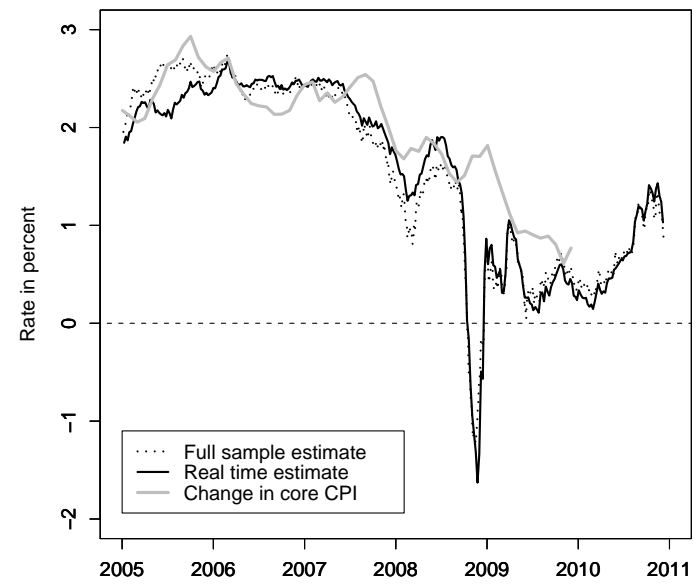

(b) Comparison to core CPI inflation.

Figure 4: Real-Time, One-Year Inflation Forecasts.

Illustration of the real-time estimates of the one-year inflations expectations from the CLR model. Included are the corresponding estimates from the full sample estimation as well as the subsequent year-over-year change in headline and core CPI, respectively.

Table 2 reports summary statistics for the model's forecasts of both headline and core CPI one and two years ahead from both the full-sample and the real-time analysis and compares its performance to that of the random walk. In general, under the root-mean-squared-error loss function, the model is able to beat the random walk at forecasting headline CPI, and is not that far behind when it comes to forecasting changes in the more stable core CPI. During this sample period, the model generally underestimated realized inflation. Bond investors likely underestimated the persistent increases in energy prices from 2003 to mid-2008. In addition, at times, TIPS yields were likely artificially elevated due to liquidity premiums, which would translate into low BEI rates and, presumably, correspondingly low model inflation forecasts.

\section{Forecasts from Macroeconomic Models and Surveys}

In this section, we compare the deflation probability forecasts from the CLR yields-only model to those obtained from simple macroeconomic models and from professional forecasters. One source for deflation probabilities is the quarterly Survey of Professional Forecasters (SPF), which provides point forecasts for CPI inflation over the next four quarters. These forecasts can be used to generate implied SPF deflation probability forecasts based on the distribution of past SPF forecast errors. Specifically, the SPF probability forecast in a particular quarter 


\begin{tabular}{|c|c|c|c|c|}
\hline \multicolumn{5}{|c|}{ Full sample analysis, 1999-2010 } \\
\hline \multirow{2}{*}{ Headline CPI } & \multicolumn{2}{|c|}{ One-year forecast } & \multicolumn{2}{|c|}{ Two-year forecast } \\
\hline & Mean & RMSE & Mean & RMSE \\
\hline Random walk & 3.96 & 212.12 & 22.66 & 130.53 \\
\hline CLR model & -105.97 & 167.43 & -97.23 & 139.72 \\
\hline \multirow{2}{*}{ Core CPI } & \multicolumn{2}{|c|}{ One-year forecast } & \multicolumn{2}{|c|}{ Two-year forecast } \\
\hline & Mean & $\overline{\mathrm{RMSE}}$ & Mean & RMSE \\
\hline Random walk & 9.32 & 55.87 & 10.32 & 59.27 \\
\hline CLR model & -64.64 & 87.08 & -59.83 & 82.64 \\
\hline
\end{tabular}

\begin{tabular}{|l|c|c||c|c|}
\hline \multicolumn{5}{|c|}{ Real-time analysis, 2005-2010 } \\
\hline \hline \multirow{2}{*}{ Headline CPI } & \multicolumn{2}{|c|}{ One-year forecast } & \multicolumn{2}{|c|}{ Two-year forecast } \\
\cline { 2 - 5 } & Mean & RMSE & Mean & RMSE \\
\hline Random walk & 32.60 & 288.81 & 99.50 & 167.30 \\
CLR model & -50.27 & 173.87 & -12.18 & 106.58 \\
\hline \hline \multirow{2}{*}{ Core CPI } & \multicolumn{2}{|c||}{ One-year forecast } & \multicolumn{2}{|c|}{ Two-year forecast } \\
\cline { 2 - 5 } & \multicolumn{2}{|c||}{ Mean } & RMSE & \multicolumn{2}{|c|}{ Mean } & RMSE \\
\hline Random walk & 22.56 & 55.80 & 22.71 & 58.61 \\
CLR model & -24.17 & 63.54 & 2.69 & 58.16 \\
\hline
\end{tabular}

Table 2: Summary Statistics for Inflation Forecast Errors.

The summary statistics for the forecast errors from the random walk and the CLR models in forecasting both headline and core CPI inflation one and two years ahead. The top panel is based on the full sample estimate generating 131 and 119 monthly forecast errors from the end of January 1999 until the end of November 2009 and November 2008, respectively. The bottom panel is based on the real-time analysis which generates 59 and 47 monthly forecast errors from the end of January 2005 until the end of November 2009 and November 2008, respectively. All numbers are measured in basis points.

assumes a normal distribution of outcomes around the point forecast with a variance equal to that of SPF CPI forecast errors from 1981:Q1 - the first quarter of SPF CPI forecasts up to that particular quarter. Rudebusch and Williams (2009) apply a similar methodology to obtain implied SPF recession probability forecasts and show that they correspond quite closely with the subjective recession probabilities, that are reported in the SPF. ${ }^{8}$ The SPF inflation forecasts and implied deflation probability forecasts are shown in Figures 5 and 6 , respectively.

It is also of interest to compare our yields-only deflation probabilities to those generated

\footnotetext{
${ }^{8}$ The SPF has long asked participants to report inflation forecast probability distributions; unfortunately, this direct subjective assessment refers to gross domestic product (GDP) price inflation on a calendar year average over calendar year average basis rather than the one-year-ahead CPI percent change relevant for the TIPS-based probabilities. (Since 2007, the SPF has also reported subjective probabilities for core CPI inflation on a calendar year basis.) To the extent they are comparable across their differing price indexes, the reported SPF deflation probabilities appear to be consistent with our model-implied deflation probabilities.
} 


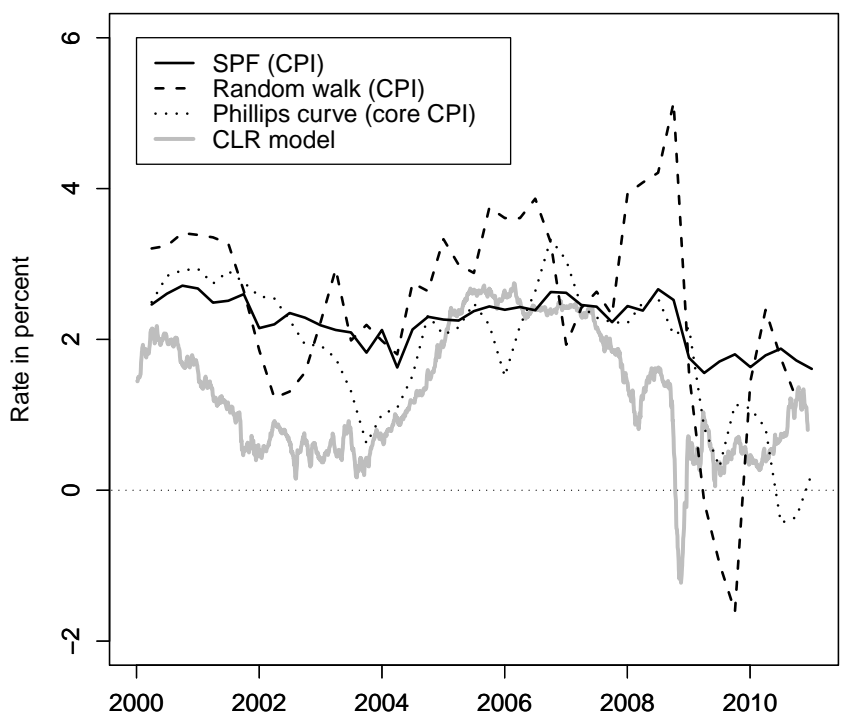

Figure 5: CPI and Core CPI Inflation Forecasts.

See main text for the description of the various inflation forecasts.

from models of inflation. From the vast macroeconomic literature, we consider two simple real-time, macroeconomic benchmarks using data and analysis that arguably were available to forecasters contemporaneously — that is, in the early to mid 2000s. The first model employs a random walk forecast of the kind recommended by Atkeson and Ohanian (2001); that is, at each point in time, inflation over the next year is projected to be the same as it was over the past year. The second model is a simple Phillips curve along the lines considered by Stock and Watson (1999) as well as Rudebusch and Svensson (1999) in which inflation depends on lagged inflation and inversely on the degree of slack. For this purpose, we simply regress the onequarter-ahead core CPI inflation on four lags of itself and one lag of the unemployment rate over the sample 1984:Q1 to 1999:Q4. ${ }^{9}$ Each quarter from 2000 through 2010, this equation is iterated ahead (using SPF real-time forecasts for unemployment) to produce four-quarterahead inflation forecasts. Probability forecasts from these models also require a distribution of likely outcomes. After the mid 1980s, U.S. output growth and inflation exhibited much less volatility than before, as detailed by Stock and Watson (2007). Therefore, like our SPF implicit forecast distribution, we assume a normal distribution of outcomes around the point

\footnotetext{
${ }^{9}$ Given the short available samples, simple Phillips curves do not yield satisfactory estimates with headline CPI. Williams (2009) estimates a similar model using the core PCE price index and gets broadly similar probabilities.
} 


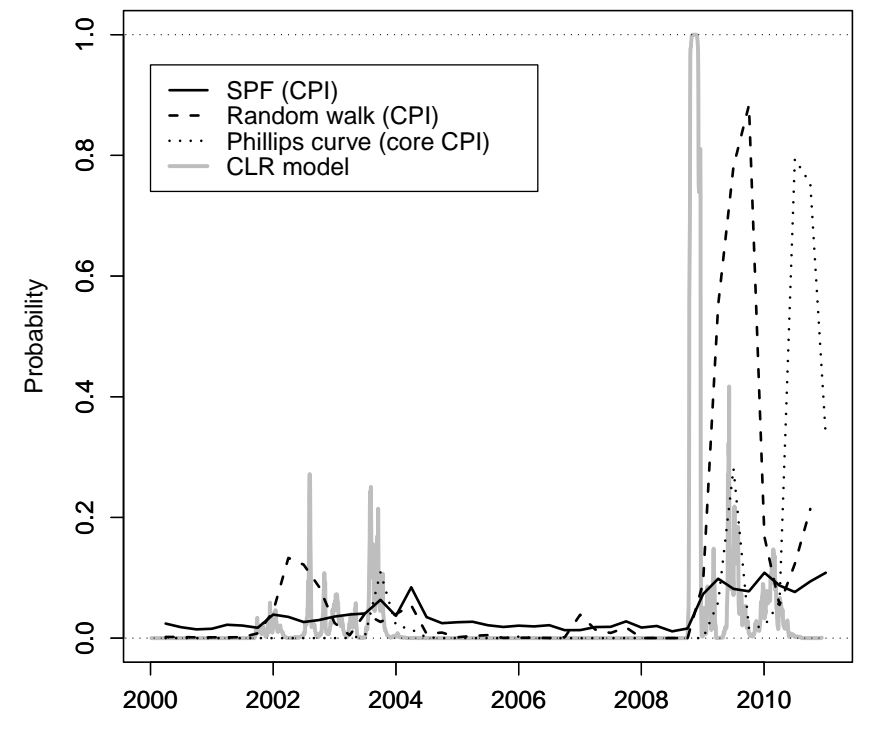

Figure 6: Probability Forecasts of of CPI and Core CPI Deflation.

See main text for the description of the various deflation probability forecasts.

forecast with a variance equal to that of the Phillips curve CPI forecast errors after 1984. The point inflation forecasts and resulting deflation probability forecasts are shown in Figures 5 and 6 , respectively.

Figures 5 and 6 also show the CLR model's inflation forecasts and deflation probabilities for comparison. During the second half of the sample, the one-year-ahead CLR inflation forecasts are generally consistent with the macroeconomic models and survey results. The divergence seen in the first few years of the sample can most likely be attributed to the TIPS liquidity issues discussed earlier, which raised TIPS yields and reduced inflation forecasts. The deflation probabilities in Figure 6 are also generally consistent with each other in that two deflationary episodes are identified following the 2001 recession and the bankruptcy of Lehman Brothers in September 2008. During other periods, all of the deflation probabilities are close to zero. During 2010, the various deflation probability forecasts have the largest differences, which is consistent with the recent heightened uncertainty about the future direction of inflation (e.g., Leduc, Rudebusch, and Weidner, 2009).

In summary, the deflationary episodes identified with the CLR model have rough parallels with those from macroeconomic models and survey forecasts, supporting the suggestion that the yields-only approach encompasses macroeconomic data quite well, even during the recent 
crisis.

\section{Alternative Forecasts from Financial Market Data}

Alternative yields-only approaches for generating deflation probabilities have been examined in a few recent studies. With respect to U.S. data, Sack (2000) showed how to generate a proxy for inflation expectations based on TIPS yields and a similar portfolio of Treasury STRIPS. The author assumed that risk-neutral investors arbitrage away differences between the payment structure of a real TIPS security (i.e., both coupons and principal) and a portfolio of nominal Treasury STRIPS that has the same payment schedule. The market-implied inflation compensation measure is the constant rate of inflation over the maturity of the portfolio that equates the prices of the TIPS security and the matching STRIPS portfolio. Higgins (2010) extended this analysis by assuming that investors believe that the inflation process has a Gaussian distribution with a constant mean and variance. Once the model's parameters are estimated, the probability of deflation over the maturity of the investment, which was five years in his analysis, can be generated as the integral over the appropriate interval of the inflation process.

Wright (2009) proposed an alternative, risk-neutral yields-only approach that is based on comparing the yields on a pair of TIPS securities that have comparable maturity dates but different issuance dates and thus different reference CPI rates; see Section 5 for further discussion of specific TIPS bond pairs. The intuition here is to take advantage of the market pricing of the deflation protection options with different strike prices that are embedded in the two TIPS bonds; i.e., the contractual feature that insures that the principal repayment cannot be less than the face value of the bond. Based on the proposed Wright (2009) approach,

a lower bound on the implied, risk-neutral deflation probability can be calculated over the period up to the maturity of the bonds.

Figure 7 shows our full-sample and real-time five-year deflation probabilities under the risk-neutral pricing measure. These deflation probabilities follow the same qualitative pattern as the one-year, real-world probabilities presented in Figures 1 and 2; that is, they rise sharply after the Lehman bankruptcy in September 2008 and then decline in light of the various policy actions taken by the Federal Reserve and other central banks over the course of the financial crisis. However, the risk-neutral probabilities are generally more persistent, and their decline through 2009 and 2010 is slower than that typically exhibited by real-world probabilities. The differences between the two sets of deflation probabilities, especially during the financial crisis, underscores the usefulness of a dynamic term structure model that allows us to generate 


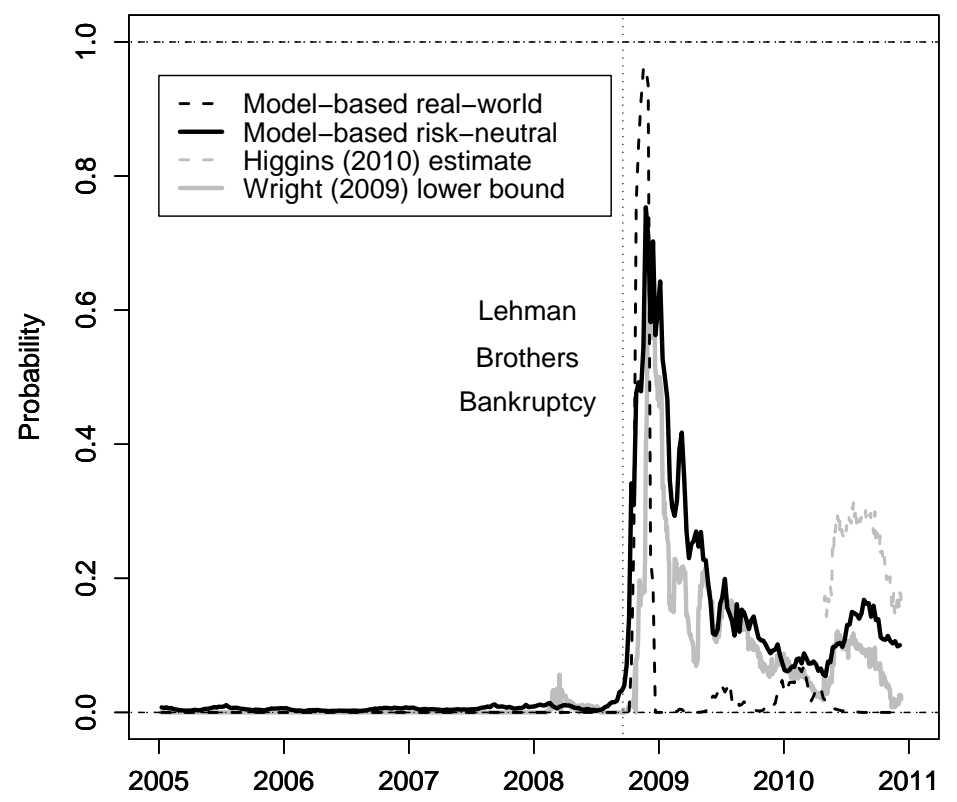

Figure 7: Five-Year-Ahead Deflation Probability Forecasts.

Illustration of the real-time probability forecasts of non-positive net inflation (i.e., deflation) under both the real-world (or $P$ ) probability measure and the risk-neutral (or $Q$ ) pricing measure over the following five years as estimated by the CLR model. Included are two alternative measures. The one following Higgins (2010) is only available since April 27, 2010. The other is our application of the lower bound calculation described in Wright (2009) to the pairs of comparable TIPS analyzed in Section 5.

and analyze both of them.

In comparing our estimates to the existing alternatives described previously, we note that, with few exceptions, our real-time risk-neutral estimates are above the Wright lower bound, but typically close to it. ${ }^{10}$ On the other hand, our estimates are well below those reported by Higgins (2010). Based on these results, we conclude that the CLR model produces very reasonable estimates of the deflation probability under the risk-neutral pricing measure, which is in line with the model's ability to fit the cross sections of nominal and real yields very well.

As discussed in Section 2.3, all yields-only approaches are vulnerable to changes in liquidity premiums in the Treasury markets that could distort the market pricing mechanism. In this regard, the Wright procedure has the advantage of not depending on differential liquidity premiums across the nominal and real Treasury markets, although liquidity issues may remain

\footnotetext{
${ }^{10}$ Maturity mismatches likely account for most violations since our estimates have constant five-year maturities, while the Wright measure varies with the maturity of the underlying TIPS bonds.
} 
across different TIPS bonds. Although these distortions directly affect the model-implied deflation probabilities, we are comfortable with the CLR model's ability to smooth through the recent excess volatility and capture the underlying trends in the data.

The most important shortcoming of the alternative yields-only approaches is that they only provide deflation probabilities under the risk-neutral pricing measure and not under the real-world pricing measure. Thus, these deflation probabilities are not comparable to those generated from macroeconomic sources. In contrast, the CLR modeling structure can generate real-world probabilities that can be used for macroeconomic policy analysis. ${ }^{11}$

Aside from TIPS bonds, derivative contracts could be a separate source of financial market data from which to generate deflation probabilities. Notably, since it provides its purchaser with protection when realized inflation exceeds a specified threshold, an inflation swap could provide a reading on the market-based deflation probability on the day the contract was struck. ${ }^{12}$ Since contracts are created every day at various possible maturities, a time-series of deflation probabilities at various maturities could be generated. However, trading volume on such swaps contracts is very limited in the U.S. ${ }^{13}$

\section{$5 \quad$ Pricing Inflation Floors with Deflation Probabilities}

TIPS coupons and principal have an asymmetrical indexation to the observed headline CPI changes. The indexation in light of accumulated inflation leads to increases in the coupon and principal payments accordingly. ${ }^{14}$ If at maturity the indexed principal payment is less than the par amount at issuance due to accumulated deflation, the payment is increased back to its par value. This embedded deflation floor protects the investor from declines in the price level. Under normal inflationary circumstances, the option value of the TIPS deflation floor is negligible since the probability of having negative accrued inflation compensation at

\footnotetext{
${ }^{11}$ The alternative approaches also generate only a single deflation probability at the forecast horizon determined by the maturity of the bonds under analysis. In contrast, the CLR model's use of the entire yield curve allows us to generate deflation probabilities for all horizons of interest.

${ }^{12}$ See Hinnerich (2008) for a discussion of the pricing of various forms of inflation-indexed derivatives. Haubrich et al. (2008) use monthly inflation swap data in their joint model of nominal and real Treasury rates.

${ }^{13}$ In addition, other inflation derivatives, such as inflation caps or floors that provide binary payments when the observed inflation rate is above or below the contracted inflation rate, are said to be available and actively traded. Given existing option pricing models, inflation-indexed derivatives could be used to extract marketbased deflation probabilities. However, aside from market liquidity issues, an important shortcoming of such an approach is that the probabilities would again be solely based on the risk-neutral pricing measures.

${ }^{14}$ As described in Gürkaynak et al. (2010), the reference CPI values used in the adjustment have an indexation lag since the Bureau of Labor Statistics publishes price index values with a one-month lag; i.e., the index for a given month is released in the middle of the subsequent month. The reference CPI is thus set to be a weighted average of the CPI for the second and third months prior to the month of maturity.
} 
maturity is very small. However, at the peak of the financial crisis in late 2008, neither the perceived nor the priced probabilities of deflation were negligible. Under these circumstances, a wedge developed between the prices of seasoned TIPS bonds with a significant amount of accrued inflation compensation and recently issued TIPS bonds that had no accumulated inflation compensation and therefore were at the deflation floor upon issuance. Grishchenko et al. (2010) used a monthly two-factor AF model to compute the value of the deflation option during the recent financial crisis and showed that its value peaked in mid-2009. In this section, we use the contingent claim pricing derived by Duffie et al. (2000) within the AF modeling framework described above to value this deflation protection option. This exercise provides a relevant application of our deflation probabilities and, as we shall see, an independent check on the overall fit of the model.

We calculate the deflation options value by comparing under the risk-neutral pricing measure the prices of a newly issued TIPS bond without any accrued inflation compensation and a seasoned TIPS bond with sufficient accrued inflation compensation. First, consider a hypothetical seasoned TIPS bond with $T$ years remaining to maturity that pays an annual coupon $C$ semi-annually. Assume this bond has accrued sufficient inflation compensation so it is impossible to reach the deflation floor before maturity. The par-coupon bond satisfying these criteria has a coupon rate determined by the equation

$$
\sum_{i=1}^{2 T} \frac{C}{2} E_{t}^{Q}\left[e^{-\int_{t}^{t_{i}} r_{s}^{R} d s}\right]+E_{t}^{Q}\left[e^{-\int_{t}^{T} r_{s}^{R} d s}\right]=1
$$

The first term is the sum of the present value of the $2 T$ coupon payments using the model's fitted real yield curve at day $t$. The second term is the discounted value of the principal payment. The coupon payment for this seasonal bond that solves this equation is denoted as $C_{S}$.

Next, consider a new TIPS bond with no accrued inflation compensation with $T$ years to maturity. Since the coupon payments are not protected against deflation, the difference is in accounting for the deflation protection on the principal payment:

$$
\sum_{i=1}^{2 T} \frac{C}{2} E_{t}^{Q}\left[e^{-\int_{t}^{t_{i}} r_{s}^{R} d s}\right]+E_{t}^{Q}\left[\frac{Q_{T}}{Q_{t}} \cdot e^{-\int_{t}^{T} r_{s}^{N} d s} \mathbf{1}_{\left\{\frac{Q_{T}}{Q_{t}}>1\right\}}\right]+E_{t}^{Q}\left[1 \cdot e^{-\int_{t}^{T} r_{s}^{N} d s} \mathbf{1}_{\left\{\frac{Q_{T}}{Q_{t}} \leq 1\right\}}\right]=1 .
$$

The first term is the same as before. The second term represents the present value of the principal payment conditional on a positive net change in the price index over the bond's maturity; i.e., $\frac{Q_{T}}{Q_{t}}>1$. Under this condition, full inflation indexation applies, and the price 
change $\frac{Q_{T}}{Q_{t}}$ is placed within the expectations operator and weighted by the probability of accumulated inflation at time $T$. The third term represents the present value of the floored TIPS principal conditional on accumulated net deflation; i.e., when the price level change is below one, $\frac{Q_{T}}{Q_{t}}$ is replaced by a value of one to provide the promised deflation protection. Since

$$
\frac{Q_{T}}{Q_{t}}=e^{\int_{t}^{T}\left(r_{s}^{N}-r_{s}^{R}\right) d s}
$$

the equation can be rewritten as

$\sum_{i=1}^{2 T} \frac{C}{2} E_{t}^{Q}\left[e^{-\int_{t}^{t_{i}} r_{s}^{R} d s}\right]+E_{t}^{Q}\left[e^{-\int_{t}^{T} r_{s}^{R} d s}\right]+\left[E_{t}^{Q}\left[e^{-\int_{t}^{T} r_{s}^{N} d s} \mathbf{1}_{\left\{\frac{Q_{T}}{Q_{t}} \leq 1\right\}}\right]-E_{t}^{Q}\left[e^{-\int_{t}^{T} r_{s}^{R} d s} \mathbf{1}_{\left\{\frac{Q_{T}}{Q_{t}} \leq 1\right\}}\right]\right]=1$,

where the last term on the left-hand side represents the net present value of the deflation protection of the principal in the TIPS contract. ${ }^{15}$ The par-coupon yield of a new hypothetical TIPS bond that solves this equation is denoted as $C_{0}$.

The difference between $C_{S}$ and $C_{0}$ is a measure of the advantage of being at the inflation adjustment floor for a newly issued TIPS bond. The black line in Figure 8 shows the difference between the $C_{S}$ and $C_{0}$ values that solve the pricing equations at the five-year maturity using our real-time model estimates. Prior to the Lehman bankruptcy, the differences between the two synthetic TIPS bond yields were quite near zero, but slightly negative. However, the yield differences jumped during the financial crisis, which is consistent with our model implied deflation probabilities shown in Figure 3. Even by the end of our sample in December 2010, the spreads remained above 5 basis points, suggesting that deflation protection was still of some value despite the fact that the model-implied deflation probabilities had reached insignificant levels months before. ${ }^{16}$

Figure 8 also compares our model-based estimates to the observed yield differences between pairs of comparable seasoned and recently issued TIPS bonds. The solid grey line represents the yield difference between a seasoned ten-year TIPS bond with approximately five years remaining to maturity and the most recently issued five-year TIPS bond. ${ }^{17}$ Since these pairs

\footnotetext{
${ }^{15}$ The appendix explains how these contingent conditional expectations are calculated within the CLR model using the contingent claim pricing results of Duffie et al. (2000).

${ }^{16}$ This spread suggests that seasoned and newly issued TIPS bonds should not be pooled to construct real yield curves, unless the prices of the recently issued TIPS are corrected for the value of the deflation protection.

${ }^{17}$ From January 3, 2005 to April 24, 2006, we use the 5-year TIPS that matured in April 2010 and the 10-year TIPS that matured in January 2010. From April 25, 2006 to April 23, 2007, we use the 5-year TIPS with maturity in April 2011 and the 10-year TIPS with maturity in January 2011. From April 24, 2007 to April 22, 2008, we use the 5-year TIPS with maturity in April 2012 and the 10-year TIPS with maturity in July 2012. From April 23, 2008 to April 22, 2009, we use the 5-year TIPS with maturity in April 2013 and the 10-year TIPS with maturity in July 2013. From April 23, 2009 to April 23, 2010, we use the 5-year TIPS with maturity in April 2014 and the 10-year TIPS with maturity in July 2014. Since April 26, 2010, we use
} 


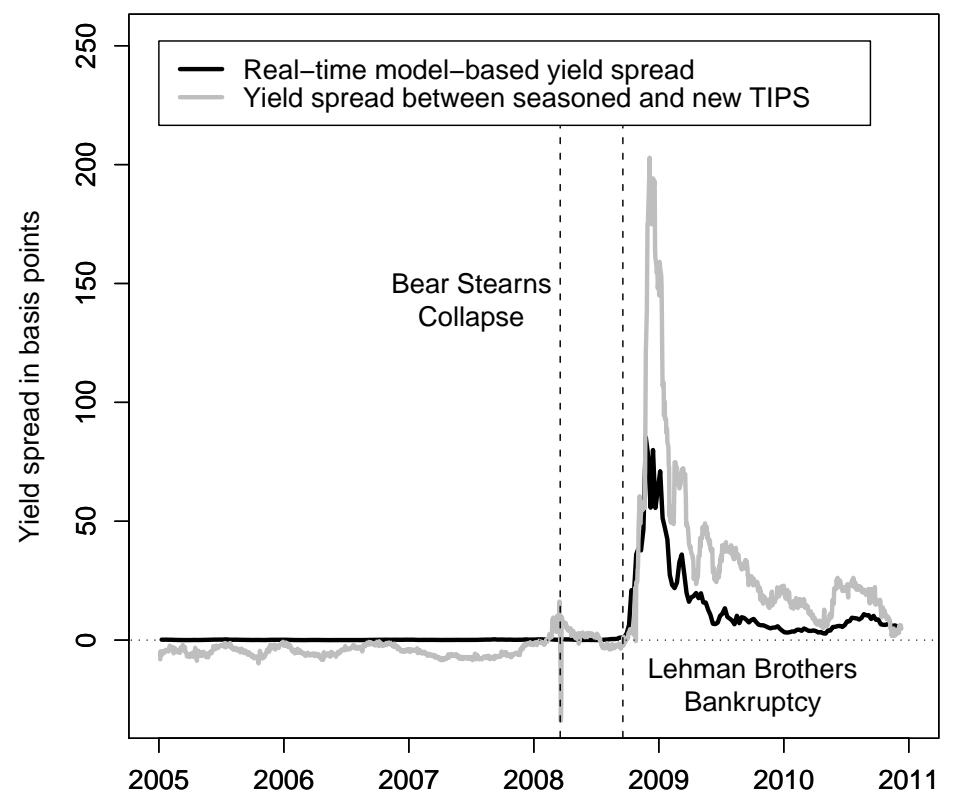

Figure 8: Value of the Deflation Protection Embedded in TIPS.

Illustration of the model-implied five-year par-coupon yield spread of a seasoned TIPS over a comparable newly issued TIPS. Included are the spread in the yield-to-maturity as reported by Bloomberg between the on-the-run pairs of seasoned and newly issued TIPS.

of TIPS bonds have similar remaining payment schedules and liquidity, their yield difference should be primarily due to the value of the embedded deflation protection option. Our realtime model estimates track the observed TIPS yield spread remarkably well, especially since the individual TIPS spreads are not used directly in the model estimation. These results provide further support for the model's underlying deflation probability forecasts. ${ }^{18}$

\section{Conclusion}

The possibility of deflation has been an important risk factor for the Federal Reserve over the past decade and, in light of the current low inflation environment, is likely to continue to be so going forward. In this paper, we use a yields-only dynamic term structure model developed by Christensen et al. (2010) to generate inflation expectations and corresponding deflation

the 5-year TIPS with maturity in April 2015 and the 10-year TIPS with maturity in July 2015.

${ }^{18}$ The model-based yield spreads are lower than the observed spreads. Incorporating stochastic volatility into the model, as in Adrian and Wu (2010), might improve the pricing of the deflation option. We are pursuing this issue in further work. 
probability forecasts that could be used directly for macroecnomic policy analysis and asset pricing purposes. A key advantage of the model is that it can be updated daily with just Treasury bond yields and used for real-time analysis, unlike macroeconomic analysis based on lower-frequency data. The model's deflation probabilities, both under the risk-neutral and real-world pricing measures, are shown to correspond well with forecasts from macroeconomic models, survey data, and other yields-only approaches in the literature. Finally, the model's ability to capture fluctuations of the value of the TIPS embedded deflation protection option provides further model validation and an example of its usefulness. 


\section{Appendix}

\section{A). The Probability of Deflation in the CLR Model}

The probability that the change in the price index is below a certain critical level $q$ equals the probability of the states of the world where

$$
\frac{Q_{t+\tau}}{Q_{t}} \leq 1+q
$$

This is equivalent to requiring

$$
\int_{t}^{t+\tau}\left(r_{s}^{N}-r_{s}^{R}\right) d s \leq \ln (1+q)
$$

Therefore, we are interested in the distributional properties of the following process:

$Y_{0, t}=\int_{0}^{t}\left(r_{s}^{N}-r_{s}^{R}\right) d s=\int_{0}^{t}\left(L_{s}^{N}+S_{s}-L_{s}^{R}-\alpha^{R} S_{s}\right) d s \quad \Rightarrow \quad d Y_{0, t}=\left(L_{t}^{N}+\left(1-\alpha^{R}\right) S_{t}-L_{t}^{R}\right) d t$

In general, the real-world $P$-dynamics of the state variables $X_{t}$ are given by

$$
d X_{t}=K^{P}\left(\theta^{P}-X_{t}\right) d t+\Sigma d W_{t}^{P}
$$

Adding the $Y_{0, t}$-process to this system, leaves us with a five-factor SDE

$$
\begin{aligned}
\left(\begin{array}{c}
d L_{t}^{N} \\
d S_{t} \\
d C_{t} \\
d L_{t}^{R} \\
d Y_{0, t}
\end{array}\right)= & \left(\begin{array}{ccccc}
\kappa_{11}^{P} & \kappa_{12}^{P} & \kappa_{13}^{P} & \kappa_{14}^{P} & 0 \\
\kappa_{21}^{P} & \kappa_{22}^{P} & \kappa_{23}^{P} & \kappa_{24}^{P} & 0 \\
\kappa_{31}^{P} & \kappa_{32}^{P} & \kappa_{33}^{P} & \kappa_{34}^{P} & 0 \\
\kappa_{41}^{P} & \kappa_{42}^{P} & \kappa_{43}^{P} & \kappa_{44}^{P} & 0 \\
0 & 0 & 0 & 0 & 0
\end{array}\right)\left(\begin{array}{c}
\theta_{1}^{P} \\
\theta_{2}^{P} \\
\theta_{3}^{P} \\
\theta_{4}^{P} \\
0
\end{array}\right) d t \\
& -\left(\begin{array}{ccccc}
\kappa_{11}^{P} & \kappa_{12}^{P} & \kappa_{13}^{P} & \kappa_{14}^{P} & 0 \\
\kappa_{21}^{P} & \kappa_{22}^{P} & \kappa_{23}^{P} & \kappa_{24}^{P} & 0 \\
\kappa_{31}^{P} & \kappa_{32}^{P} & \kappa_{33}^{P} & \kappa_{34}^{P} & 0 \\
\kappa_{41}^{P} & \kappa_{42}^{P} & \kappa_{43}^{P} & \kappa_{44}^{P} & 0 \\
-1 & -\left(1-\alpha^{R}\right) & 0 & 1 & 0
\end{array}\right)\left(\begin{array}{c}
L_{t}^{N} \\
S_{t} \\
C_{t} \\
L_{t}^{R} \\
Y_{0, t}
\end{array}\right) d t+\left(\begin{array}{ccccc}
\sigma_{1} & 0 & 0 & 0 & 0 \\
0 & \sigma_{2} & 0 & 0 & 0 \\
0 & 0 & \sigma_{3} & 0 & 0 \\
0 & 0 & 0 & \sigma_{4} & 0 \\
0 & 0 & 0 & 0 & 0
\end{array}\right)\left(\begin{array}{c}
d W_{t}^{1, P} \\
d W_{t}^{2, P} \\
d W_{t}^{3, P} \\
d W_{t}^{4, P} \\
d W_{t}^{5, P}
\end{array}\right),
\end{aligned}
$$

where $Z_{0, t}=\left(L_{t}^{N}, S_{t}, C_{t}, L_{t}^{R}, Y_{0, t}\right)$ represents the augmented state vector.

This is a system of Gaussian state variables, and all we need to describe its distributional properties is to calculate the conditional mean vector and covariance matrix. If we define $m^{P}(0, t)=E^{P}\left[Z_{0, t} \mid \mathcal{F}_{0}\right]$, it follows from Duffie (1996), p. 293, that the vector of conditional 
means is given by the solution to the following system of ODEs:

$$
\frac{d m^{P}(0, t)}{d t}=a^{P}+b^{P} m^{P}(0, t), \quad m_{0}^{P}=Z_{0}
$$

where

$$
a^{P}=\left(\begin{array}{ccccc}
\kappa_{11}^{P} & \kappa_{12}^{P} & \kappa_{13}^{P} & \kappa_{14}^{P} & 0 \\
\kappa_{21}^{P} & \kappa_{22}^{P} & \kappa_{23}^{P} & \kappa_{24}^{P} & 0 \\
\kappa_{31}^{P} & \kappa_{32}^{P} & \kappa_{33}^{P} & \kappa_{34}^{P} & 0 \\
\kappa_{41}^{P} & \kappa_{42}^{P} & \kappa_{43}^{P} & \kappa_{44}^{P} & 0 \\
0 & 0 & 0 & 0 & 0
\end{array}\right)\left(\begin{array}{c}
\theta_{1}^{P} \\
\theta_{2}^{P} \\
\theta_{3}^{P} \\
\theta_{4}^{P} \\
0
\end{array}\right) \text { and } b^{P}=-\left(\begin{array}{ccccc}
\kappa_{11}^{P} & \kappa_{12}^{P} & \kappa_{13}^{P} & \kappa_{14}^{P} & 0 \\
\kappa_{21}^{P} & \kappa_{22}^{P} & \kappa_{23}^{P} & \kappa_{24}^{P} & 0 \\
\kappa_{31}^{P} & \kappa_{32}^{P} & \kappa_{33}^{P} & \kappa_{34}^{P} & 0 \\
\kappa_{41}^{P} & \kappa_{42}^{P} & \kappa_{43}^{P} & \kappa_{44}^{P} & 0 \\
-1 & -\left(1-\alpha^{R}\right) & 0 & 1 & 0
\end{array}\right)
$$

According to the same source, the conditional covariance matrix can be calculated as

$$
\frac{d V^{P}(t)}{d t}=b^{P} V^{P}(t)+V^{P}(t)\left(b^{P}\right)^{\prime}+\overline{\Sigma \Sigma}^{\prime}, \quad V^{P}(0)=0
$$

where $b^{P}$ is as above and

$$
\bar{\Sigma}=\left(\begin{array}{ccccc}
\sigma_{1} & 0 & 0 & 0 & 0 \\
0 & \sigma_{2} & 0 & 0 & 0 \\
0 & 0 & \sigma_{3} & 0 & 0 \\
0 & 0 & 0 & \sigma_{4} & 0 \\
0 & 0 & 0 & 0 & 0
\end{array}\right) .
$$

We solve both systems of ODEs with a standard fourth-order, Runge-Kutta method. Given solutions for $m_{0, t}^{P}$ and $V_{t}^{P}$, we focus on the elements related to $Y_{0, t}$ which allows us to write

$$
Y_{t, t+\tau}=\int_{t}^{t+\tau}\left(r_{s}^{N}-r_{s}^{R}\right) d s \sim N\left(m_{Y}^{P}(t, \tau), \sigma_{Y}^{P}(\tau)^{2}\right)
$$

Now, the probability of the change in the price index being below the critical level $q$ is

$\operatorname{Prob}_{t}\left(Y_{t, t+\tau} \leq \ln (1+q)\right)=\operatorname{Prob}_{t}\left(\frac{Y_{t, t+\tau}-m_{Y}^{P}(t, \tau)}{\sigma_{Y}^{P}(\tau)} \leq \frac{\ln (1+q)-m_{Y}^{P}(t, \tau)}{\sigma_{Y}^{P}(\tau)}\right)=\Phi\left(\frac{\ln (1+q)-m_{Y}^{P}(t, \tau)}{\sigma_{Y}^{P}(\tau)}\right)$.

\section{$B)$. Calculation of the NPV of the TIPS Principal Deflation Protection}

In general, we are interested in finding the net present value (NPV) of terminal payoffs from TIPS bonds contingent on the cumulated inflation being below some critical value $q$; 
specifically, the following difference is of interest

$$
E_{t}^{Q}\left[e^{-\int_{t}^{T} r_{s}^{N} d s} \mathbf{1}_{\left\{\frac{Q_{T}}{Q_{t}} \leq 1+q\right\}}\right]-E_{t}^{Q}\left[e^{-\int_{t}^{T} r_{s}^{R} d s} \mathbf{1}_{\left\{\frac{Q_{T}}{Q_{t}} \leq 1+q\right\}}\right]
$$

Thus, the states of the world of interest are characterized by

$$
\frac{Q_{T}}{Q_{t}} \leq 1+q \Longleftrightarrow Y_{t, T}=\int_{t}^{T}\left(r_{s}^{N}-r_{s}^{R}\right) d s \leq \ln (1+q)
$$

To price these terminal principal payments, we need the dynamics of the state variables under the risk-neutral $Q$-measure, such that

$$
\left(\begin{array}{c}
d L_{t}^{N} \\
d S_{t} \\
d C_{t} \\
d L_{t}^{R} \\
d Y_{0, t}
\end{array}\right)=-\left(\begin{array}{ccccc}
0 & 0 & 0 & 0 & 0 \\
0 & \lambda & -\lambda & 0 & 0 \\
0 & 0 & \lambda & 0 & 0 \\
0 & 0 & 0 & 0 & 0 \\
-1 & -\left(1-\alpha^{R}\right) & 0 & 1 & 0
\end{array}\right)\left(\begin{array}{c}
L_{t}^{N} \\
S_{t} \\
C_{t} \\
L_{t}^{R} \\
Y_{0, t}
\end{array}\right) d t+\left(\begin{array}{ccccc}
\sigma_{1} & 0 & 0 & 0 & 0 \\
0 & \sigma_{2} & 0 & 0 & 0 \\
0 & 0 & \sigma_{3} & 0 & 0 \\
0 & 0 & 0 & \sigma_{4} & 0 \\
0 & 0 & 0 & 0 & 0
\end{array}\right)\left(\begin{array}{c}
d W_{t}^{1, Q} \\
d W_{t}^{2, Q} \\
d W_{t}^{3, Q} \\
d W_{t}^{4, Q} \\
d W_{t}^{5, Q}
\end{array}\right) .
$$

Now, define the following two intermediate functions

$$
\psi^{1}(\bar{B}, t, T)=E_{t}^{Q}\left[e^{-\int_{t}^{T} r_{s}^{R} d s} e^{\bar{B}^{\prime} Z_{t, T}}\right]
$$

and

$$
\psi^{2}(\bar{B}, t, T)=E_{t}^{Q}\left[e^{-\int_{t}^{T} r_{s}^{N} d s} e^{\bar{B}^{\prime} Z_{t, T}}\right]
$$

In order to calculate $\psi^{1}(\bar{B}, t, T)$ and $\psi^{2}(\bar{B}, t, T)$, we summarize the risk-neutral dynamics by the following matrices and vectors:

$$
K^{Q}=\left(\begin{array}{ccccc}
0 & 0 & 0 & 0 & 0 \\
0 & \lambda & -\lambda & 0 & 0 \\
0 & 0 & \lambda & 0 & 0 \\
0 & 0 & 0 & 0 & 0 \\
-1 & -\left(1-\alpha^{R}\right) & 0 & 1 & 0
\end{array}\right), \quad \Sigma=\left(\begin{array}{ccccc}
\sigma_{1} & 0 & 0 & 0 & 0 \\
0 & \sigma_{2} & 0 & 0 & 0 \\
0 & 0 & \sigma_{3} & 0 & 0 \\
0 & 0 & 0 & \sigma_{4} & 0 \\
0 & 0 & 0 & 0 & 0
\end{array}\right), \quad \rho^{N}=\left(\begin{array}{c}
1 \\
1 \\
0 \\
0 \\
0
\end{array}\right), \quad \rho^{R}=\left(\begin{array}{c}
0 \\
\alpha^{R} \\
0 \\
1 \\
0
\end{array}\right)
$$

From Duffie et al. (2000), it follows that

$$
\psi^{1}(\bar{B}, t, T)=\exp \left(B_{\psi^{1}}(t, T)^{\prime} Z_{t, t}+A_{\psi^{1}}(t, T)\right)
$$


where $B_{\psi^{1}}(t, T)$ and $A_{\psi^{1}}(t, T)$ are the solutions to the following system of ODEs:

$$
\begin{aligned}
& \frac{d B_{\psi^{1}}(t, T)}{d t}=\rho^{R}+\left(K^{Q}\right)^{\prime} B_{\psi^{1}}(t, T), \quad B_{\psi^{1}}(T, T)=\bar{B} \\
& \frac{d A_{\psi^{1}}(t, T)}{d t}=-\frac{1}{2} \sum_{j=1}^{5}\left(\bar{\Sigma}^{\prime} B_{\psi^{1}}(t, T) B_{\psi^{1}}(t, T)^{\prime} \bar{\Sigma}\right)_{j, j}, \quad A_{\psi^{1}}(T, T)=0 .
\end{aligned}
$$

This system of ODEs can be solved analytically, and the solution is provided in the following proposition.

\section{Proposition 1:}

If the state variables are given by $Z_{t, T}=\left(L_{t}^{N}, S_{t}, C_{t}, L_{t}^{R}, Y_{t, T}\right)$ and the real instantaneous risk-free rate is given by $r_{t}^{R}=\left(\rho^{R}\right)^{\prime} X_{t}$, then

$\psi^{1}(\bar{B}, t, T)=\exp \left(B_{\psi^{1}}^{1}(t, T) L_{t}^{N}+B_{\psi^{1}}^{2}(t, T) S_{t}+B_{\psi^{1}}^{3}(t, T) C_{t}+B_{\psi^{1}}^{4}(t, T) L_{t}^{R}+B_{\psi^{1}}^{5}(t, T) Y_{t, t}+A_{\psi^{1}}(t, T)\right)$

where $^{19}$

$B_{\psi^{1}}^{1}(t, T)=\bar{B}^{1}+\bar{B}^{5}(T-t)$,

$B_{\psi^{1}}^{2}(t, T)=e^{-\lambda(T-t)} \bar{B}^{2}-\left[\alpha^{R}-\left(1-\alpha^{R}\right) \bar{B}^{5}\right] \frac{1-e^{-\lambda(T-t)}}{\lambda}$,

$B_{\psi^{1}}^{3}(t, T)=e^{-\lambda(T-t)} \bar{B}^{3}+\lambda(T-t) e^{-\lambda(T-t)} \bar{B}^{2}+\left[\alpha^{R}-\left(1-\alpha^{R}\right) \bar{B}^{5}\right]\left\{(T-t) e^{-\lambda(T-t)}-\frac{1-e^{-\lambda(T-t)}}{\lambda}\right\}$,

$B_{\psi^{1}}^{4}(t, T)=\bar{B}^{4}-\left(1+\bar{B}^{5}\right)(T-t)$,

$B_{\psi^{1}}^{5}(t, T)=\bar{B}^{5}$,

and $^{20}$

\footnotetext{
${ }^{19}$ The calculations leading to this result are available upon request.
}

${ }^{20}$ As we will see later, we need to evaluate $A_{\psi^{1}}(t, T)$ (and $A_{\psi^{2}}(t, T)$ below) at $\bar{B}^{5}=0$. Since the analytical $A_{\psi^{i}}(t, T)$-functions are not well-defined in this case (while the underlying ODEs obviously are), we approximate them by using $\bar{B}^{5}=10^{-7}$ instead. 


$$
\begin{aligned}
A_{\psi^{1}}(t, T)= & -\frac{\sigma_{1}^{2}}{6 \bar{B}^{5}}\left[\left(\bar{B}^{1}\right)^{3}-\left(\bar{B}^{1}+\bar{B}^{5}(T-t)\right)^{3}\right] \\
& +\sigma_{2}^{2}\left[\alpha^{R}-\left(1-\alpha^{R}\right) \bar{B}^{5}+\lambda \bar{B}^{2}\right]^{2} \frac{1-e^{-2 \lambda(T-t)}}{4 \lambda^{3}}+\frac{\sigma_{2}^{2}}{2} \frac{\left[\alpha^{R}-\left(1-\alpha^{R}\right) \bar{B}^{5}\right]^{2}}{\lambda^{2}}(T-t) \\
& -\sigma_{2}^{2}\left[\alpha^{R}-\left(1-\alpha^{R}\right) \bar{B}^{5}+\lambda \bar{B}^{2}\right]\left[\alpha^{R}-\left(1-\alpha^{R}\right) \bar{B}^{5}\right] \frac{1-e^{-\lambda(T-t)}}{\lambda^{3}} \\
& +\sigma_{3}^{2}\left[\alpha^{R}-\left(1-\alpha^{R}\right) \bar{B}^{5}+\lambda \bar{B}^{3}\right]^{2} \frac{1-e^{-2 \lambda(T-t)}}{4 \lambda^{3}}+\frac{\sigma_{3}^{2}}{2} \frac{\left[\alpha^{R}-\left(1-\alpha^{R}\right) \bar{B}^{5}\right]^{2}}{\lambda^{2}}(T-t) \\
& +\frac{\sigma_{3}^{2}}{2}\left[\alpha^{R}-\left(1-\alpha^{R}\right) \bar{B}^{5}+\lambda \bar{B}^{2}\right]^{2}\left[-\frac{1}{2 \lambda}(T-t)^{2} e^{-2 \lambda(T-t)}-\frac{1}{2 \lambda^{2}}(T-t) e^{-2 \lambda(T-t)}+\frac{1-e^{-2 \lambda(t-t)}}{4 \lambda^{3}}\right] \\
& -\sigma_{3}^{2}\left[\alpha^{R}-\left(1-\alpha^{R}\right) \bar{B}^{5}+\lambda \bar{B}^{3}\right]\left[\alpha^{R}-\left(1-\alpha^{R}\right) \bar{B}^{5}\right] \frac{1-e^{-\lambda(T-t)}}{\lambda^{3}} \\
& +\sigma_{3}^{2} \frac{\left[\alpha^{R}-\left(1-\alpha^{R}\right) \bar{B}^{5}+\lambda \bar{B}^{3}\right]\left[\alpha^{R}-\left(1-\alpha^{R}\right) \bar{B}^{5}+\lambda \bar{B}^{2}\right]}{\lambda}\left[-\frac{1}{2 \lambda}(T-t) e^{-2 \lambda(T-t)}+\frac{1-e^{-2 \lambda(T-t)}}{4 \lambda^{2}}\right] \\
& -\sigma_{3}^{2} \frac{\left[\alpha^{R}-\left(1-\alpha^{R}\right) \bar{B}^{5}\right]\left[\alpha^{R}-\left(1-\alpha^{R}\right) \bar{B}^{5}+\lambda \bar{B}^{2}\right]}{\lambda}\left[-\frac{1}{\lambda}(T-t) e^{-\lambda(T-t)}+\frac{1-e^{-\lambda(T-t)}}{\lambda^{2}}\right] \\
& +\frac{\sigma_{4}^{2}}{6\left(1+\bar{B}^{5}\right)}\left[\left(\bar{B}^{4}\right)^{3}-\left(\bar{B}^{4}-\left(1+\bar{B}^{5}\right)(T-t)\right)^{3}\right] .
\end{aligned}
$$

Using a similar approach, it holds that

$$
\psi^{2}(\bar{B}, t, T)=\exp \left(B_{\psi^{2}}(t, T)^{\prime} Z_{t, t}+A_{\psi^{2}}(t, T)\right)
$$

where $B_{\psi^{2}}(t, T)$ and $A_{\psi^{2}}(t, T)$ are the solutions to the following system of ODEs

$$
\begin{aligned}
& \frac{d B_{\psi^{2}}(t, T)}{d t}=\rho^{N}+\left(K^{Q}\right)^{\prime} B_{\psi^{2}}(t, T), \quad B_{\psi^{2}}(T, T)=\bar{B} \\
& \frac{d A_{\psi^{2}}(t, T)}{d t}=-\frac{1}{2} \sum_{j=1}^{5}\left(\Sigma^{\prime} B_{\psi^{2}}(t, T) B_{\psi^{2}}(t, T)^{\prime} \Sigma\right)_{j, j}, \quad A_{\psi^{2}}(T, T)=0 .
\end{aligned}
$$

This system can also be solved analytically, and the solution is provided in the following proposition.

\section{Proposition 2:}

If the state variables are given by $Z_{t, T}=\left(L_{t}^{N}, S_{t}, C_{t}, L_{t}^{R}, Y_{t, T}\right)$ and the nominal instantaneous risk-free rate is given by $r_{t}^{N}=\left(\rho^{N}\right)^{\prime} X_{t}$, then

$\psi^{2}(\bar{B}, t, T)=\exp \left(B_{\psi^{2}}^{1}(t, T) L_{t}^{N}+B_{\psi^{2}}^{2}(t, T) S_{t}+B_{\psi^{2}}^{3}(t, T) C_{t}+B_{\psi^{2}}^{4}(t, T) L_{t}^{R}+B_{\psi^{2}}^{5}(t, T) Y_{t, t}+A_{\psi^{2}}(t, T)\right)$ 
where $^{21}$

$$
\begin{aligned}
& B_{\psi^{2}}^{1}(t, T)=\bar{B}^{1}-\left(1-\bar{B}^{5}\right)(T-t), \\
& B_{\psi^{2}}^{2}(t, T)=e^{-\lambda(T-t)} \bar{B}^{2}-\left[1-\left(1-\alpha^{R}\right) \bar{B}^{5}\right] \frac{1-e^{-\lambda(T-t)}}{\lambda}, \\
& B_{\psi^{2}}^{3}(t, T)=e^{-\lambda(T-t)} \bar{B}^{3}+\lambda(T-t) e^{-\lambda(T-t)} \bar{B}^{2}+\left[1-\left(1-\alpha^{R}\right) \bar{B}^{5}\right]\left\{(T-t) e^{-\lambda(T-t)}-\frac{1-e^{-\lambda(T-t)}}{\lambda}\right\}, \\
& B_{\psi^{2}}^{4}(t, T)=\bar{B}^{4}-\bar{B}^{5}(T-t), \\
& B_{\psi^{2}}^{5}(t, T)=\bar{B}^{5},
\end{aligned}
$$

and

$$
\begin{aligned}
A_{\psi^{2}}(t, T)= & \frac{\sigma_{1}^{2}}{6\left(1-\bar{B}^{5}\right)}\left[\left(\bar{B}^{1}\right)^{3}-\left(\bar{B}^{1}-\left(1-\bar{B}^{5}\right)(T-t)\right)^{3}\right] \\
& +\sigma_{2}^{2}\left[1-\left(1-\alpha^{R}\right) \bar{B}^{5}+\lambda \bar{B}^{2}\right]^{2} \frac{1-e^{-2 \lambda(T-t)}}{4 \lambda^{3}}+\frac{\sigma_{2}^{2}}{2} \frac{\left[1-\left(1-\alpha^{R}\right) \bar{B}^{5}\right]^{2}}{\lambda^{2}}(T-t) \\
& -\sigma_{2}^{2}\left[1-\left(1-\alpha^{R}\right) \bar{B}^{5}+\lambda \bar{B}^{2}\right]\left[1-\left(1-\alpha^{R}\right) \bar{B}^{5}\right] \frac{1-e^{-\lambda(T-t)}}{\lambda^{3}} \\
& +\sigma_{3}^{2}\left[1-\left(1-\alpha^{R}\right) \bar{B}^{5}+\lambda \bar{B}^{3}\right]^{2} \frac{1-e^{-2 \lambda(T-t)}}{4 \lambda^{3}}+\frac{\sigma_{3}^{2}}{2} \frac{\left[1-\left(1-\alpha^{R}\right) \bar{B}^{5}\right]^{2}}{\lambda^{2}}(T-t) \\
& +\frac{\sigma_{3}^{2}}{2}\left[1-\left(1-\alpha^{R}\right) \bar{B}^{5}+\lambda \bar{B}^{2}\right]^{2}\left[-\frac{1}{2 \lambda}(T-t)^{2} e^{-2 \lambda(T-t)}-\frac{1}{2 \lambda^{2}}(T-t) e^{-2 \lambda(T-t)}+\frac{1-e^{-2 \lambda(t-t)}}{4 \lambda^{3}}\right] \\
& -\sigma_{3}^{2}\left[1-\left(1-\alpha^{R}\right) \bar{B}^{5}+\lambda \bar{B}^{3}\right]\left[1-\left(1-\alpha^{R}\right) \bar{B}^{5}\right] \frac{1-e^{-\lambda(T-t)}}{\lambda^{3}} \\
& +\sigma_{3}^{2}\left[1-\left(1-\alpha^{R}\right) \bar{B}^{5}+\lambda \bar{B}^{3}\right]\left[1-\left(1-\alpha^{R}\right) \bar{B}^{5}+\lambda \bar{B}^{2}\right] \\
\lambda & \left.-\frac{1}{2 \lambda}(T-t) e^{-2 \lambda(T-t)}+\frac{1-e^{-2 \lambda(T-t)}}{4 \lambda^{2}}\right] \\
& -\sigma_{3}^{2} \frac{\left.1-\left(1-\alpha^{R}\right) \bar{B}^{5}\right]\left[1-\left(1-\alpha^{R}\right) \bar{B}^{5}+\lambda \bar{B}^{2}\right]}{\lambda}\left[-\frac{1}{\lambda}(T-t) e^{-\lambda(T-t)}+\frac{1-e^{-\lambda(T-t)}}{\lambda^{2}}\right] \\
& +\frac{\sigma_{4}^{2}}{6 \bar{B}^{5}}\left[\left(\bar{B}^{4}\right)^{3}-\left(\bar{B}^{4}-\bar{B}^{5}(T-t)\right)^{3}\right] .
\end{aligned}
$$

With these results at our disposal, we can turn our attention to the pricing of the deflation protection in the TIPS contract. From Duffie et al. (2000), it follows that

$$
\begin{aligned}
E_{t}^{Q}\left[e^{-\int_{t}^{T} r_{s}^{R} d s} e^{\bar{B}^{\prime} Z_{t, T}} \mathbf{1}_{\left\{b^{\prime} Z_{t, T} \leq z\right\}}\right] & =\frac{\psi^{1}(\bar{B}, t, T)}{2} \\
& -\frac{1}{\pi} \int_{0}^{\infty} \frac{\operatorname{Im}\left\{e^{-i v z} \psi^{1}(\bar{B}+i v b, t, T)\right\}}{v} d v
\end{aligned}
$$

\footnotetext{
${ }^{21}$ The calculations leading to this result are available upon request.
} 
and

$$
\begin{aligned}
E_{t}^{Q}\left[e^{-\int_{t}^{T} r_{s}^{N} d s} e^{\bar{B}^{\prime} Z_{t, T}} \mathbf{1}_{\left\{b^{\prime} Z_{t, T} \leq z\right\}}\right] & =\frac{\psi^{2}(\bar{B}, t, T)}{2} \\
& -\frac{1}{\pi} \int_{0}^{\infty} \frac{\operatorname{Im}\left\{e^{-i v z} \psi^{2}(\bar{B}+i v b, t, T)\right\}}{v} d v
\end{aligned}
$$

Since we interested in the condition

$$
Y_{t, T}=\int_{t}^{T}\left(r_{s}^{N}-r_{s}^{R}\right) d s \leq \ln (1+q)
$$

the expectations above should be evaluated at

$$
b=\left(\begin{array}{c}
0 \\
0 \\
0 \\
0 \\
1
\end{array}\right) \quad \text { and } z=\ln (1+q) \text {. }
$$

Furthermore, we have zero boundary values at maturity so

$$
\bar{B}=\left(\begin{array}{l}
0 \\
0 \\
0 \\
0 \\
0
\end{array}\right)
$$

The functions $\frac{\operatorname{Im}\left\{e^{-i v z} \psi^{1}(\bar{B}+i v b, t, T)\right\}}{v}$ and $\frac{\operatorname{Im}\left\{e^{-i v z} \psi^{2}(\bar{B}+i v b, t, T)\right\}}{v}$ that need to be integrated in order to calculate the NPV of the TIPS deflation protection typically have converged to zero for values of $v$ above 500. Thus, we approximate the infinite integral in the pricing formulas by capping $v$ at 1000 to err on the side of conservatism and use a step size of $\Delta v=0.01$ in the numerical approximation, which is sufficient since the functions are clearly smooth. 


\section{References}

Adrian, Tobias and Hao Wu, 2010, "The Term Structure of Inflation Expectations," Federal Reserve Bank of New York Staff Reports \#362.

Atkeson, A. and L.E. Ohanian, 2001, "Are Phillips Curves Useful for Forecasting Inflation?," Federal Reserve Bank of Minneapolis Quarterly Review 25(1), 2-11.

Bernanke Ben S., 2003, “An Unwelcome Fall in Inflation?," Speech on July 23, 2003.

Bernanke Ben S., 2010, "Monetary Policy and the Housing Bubble," Speech on January 3, 2010.

Bordo, Michael and Andrew Filardo, 2005, "Deflation And Monetary Policy In A Historical Perspective: Remembering The Past Or Being Condemned To Repeat It?," Economic Policy, 20(44,Oct), 799-844.

Campbell, John Y., Robert J. Shiller, and Luis M. Viceira, 2009, "Understanding InflationIndexed Bond Markets," Brookings Papers on Economic Activity, Spring, 79-120.

Christensen, Jens H. E., Francis X. Diebold, and Glenn D. Rudebusch, 2010, "The Affine Arbitrage-Free Class of Nelson-Siegel Term Structure Models," Federal Reserve Bank of San Francisco Working Paper 2007-20. Forthcoming in Journal of Econometrics.

Christensen, Jens H. E., Jose A. Lopez, and Glenn D. Rudebusch, 2010, "Inflation Expectations and Risk Premiums in an Arbitrage-Free Model of Nominal and Real Bond Yields," Journal of Money, Credit and Banking, Supplement to Vol. 42, no. 6, 143-178.

Diebold, Francis X. and Glenn D. Rudebusch, 1989, "Long Memory and Persistence in Aggregate Output," Journal of Monetary Economics, 24, 189-209.

Duffee, Gregory R., 2002, "Term Premia and Interest Rate Forecasts in Affine Models," Journal of Finance, Vol. 57, 405-443.

Duffie, Darrell, 1996, Dynamic Asset Pricing Theory - Second Edition, Princeton University Press.

Duffie, Darrell, Jun Pan, and Kenneth Singleton, 2000, "Transform Analysis and Asset Pricing for Affine Jump Diffusions," Econometrica, Vol. 68, 1343-1376. 
Grishchenko, Olesya V., Joel Vanden, and Jianing Zhang, 2010, "The Information Content of the Embedded Deflation Option in TIPS," manuscript, Smeal College of Business, Pennsylvania State University.

Gürkaynak, Refet S., Brian Sack, and Jonathan H. Wright, 2007, "The U.S. Treasury Yield Curve: 1961 to the Present," Journal of Monetary Economics, Vol. 54, 2291-2304.

Gürkaynak, Refet S., Brian Sack, and Jonathan H. Wright, 2010, "The TIPS Yield Curve and Inflation Compensation," American Economic Journal: Macroeconomics, Vol. 2, No. 1, 70-92.

Haubrich, J., G. Pennacchi, and P. Ritchken, 2008, "Estimating Real and Nominal Term Structures using Treasury Yields, Inflation, Inflation Forecasts, and Inflation Swap Rates," Federal Reserve Bank of Cleveland Working Paper \#2008-10.

Higgins, Patrick, 2010, "Technical details for computing deflation probabilities with TIPS prices," manuscript, Federal Reserve Bank of Atlanta.

Hinnerich, Mia, 2008, "Inflation-Indexed Swaps and Swaptions," Journal of Banking and Finance, Vol. 32, 2293-2306.

Kumar, Manmohan, Taimur Baig, Jrg Decressin, Chris Faulkner-MacDonagh, and Tarhan Feyzioglu, 2003, "Deflation: Determinants, Risks, and Policy Options," IMF Occasional Paper \#221. (Washington: International Monetary Fund).

Leduc, Sylvain, Glenn D. Rudebusch, and Justin Weidner, 2009, "Disagreement about the Inflation Outlook," Federal Reserve Bank of San Francisco Economic Letter, \#2009-31, October 5 .

Rudebusch, Glenn D. and Lars Svensson, 1999, "Policy Rules for Inflation Targeting." in Monetary Policy Rules, ed. by J. Taylor, University of Chicago Press: Chicago, 203-246.

Rudebusch, Glenn D. and John C. Williams, 2009, "Forecasting Recessions: The Puzzle of the Enduring Power of the Yield Curve," Journal of Business and Economic Statistics, $27(4), 492-503$.

Sack, Brian, 2000, "Deriving Inflation Expectations from Nominal and Inflation-Indexed Treasury Yields," Finance and Economics Discussion Series No. 33, Federal Reserve Board. 
Stock, J.H. and M.W. Watson, 1999, "Forecasting Inflation," Journal of Monetary Economics, Vol. 44, No. 2, 293-335.

Stock, J.H. and M.W. Watson, 2007, "Why Has U.S. Inflation Become Harder to Forecast?," Journal of Money, Credit, and Banking, Supplement to Vol. 39, no. 1, 3-33.

Williams, J.C., 2009, "The Risk of Deflation," Federal Reserve Bank of San Francisco Economic Letter, \# 2009-12, March 27.

Wright, Jonathan H., 2009, "Comment on Understanding Inflation-Indexed Bond Markets," Brookings Papers on Economic Activity, Spring, 126-138. 